\title{
ANALYSIS OF INFILL FRAMES USING NEURAL NETWORKS
}

\author{
V. Lavanya ${ }^{1}$, K. Rowena ${ }^{2}$, P. Anuradha ${ }^{3}$, N. Murali Krishna ${ }^{4}$ \\ ${ }^{1}$ Post Graduate Student, Department of Civil Engineering, Osmania University, Telangana, India \\ ${ }^{2}$ Under Graduate Student, Department of Civil Engineering, Osmania University, Telangana, India \\ ${ }^{3}$ Research Scholar, Assistant Professor, Department of Civil Engineering, Osmania University, Telangana, India \\ ${ }^{4}$ Professor, Department of Civil Engineering, Osmania University, Telangana, India
}

\begin{abstract}
High raised buildings are vulnerable to the lateral loads caused during natural calamities like earthquakes and cyclones. Lateral loads always affect the stability of structures. The shear walls, which are provided to resist these lateral forces, are often considered undesirable from utility point of view as they come in the way of vehicular movement in the parking area. Methods to evaluate the lateral strength from infill wall panels are studied here. In this paper, the contribution offered from infill walls to the lateral strength of the building is evaluated using a combination of FEM approach and Neural Networks. Since the integral action of the wall panels with the bounding frame is considered in this approach, the frame is called as infill frame. In the study the infill wall contribution is replaced using two diagonal struts joining the opposite corners of the frame. The Finite Element package MSC Nastran is used to evaluate the infill contribution. Frames with different aspect ratios of span to height, with and without wall openings are analysed. The strain energy of the infill frame is equated to the strain energy of frame with diagonal struts, from which the width of the equivalent struts is obtained. The equivalent diagonal struts are provided joining the opposite corners of the frame. In the present study the non linear behaviour of concrete has also been taken into consideration. To make the method more widely applicable, a large data bank with varying parameters of span/depth, beam/column sections, with and without infill openings and different grades of concrete is generated which shall be used for training a BOPN based neural net paradigm. The trained neural net is expected to furnish the width of equivalent strut, which can readily be used in the structural analysis of framed buildings. The utility of the study enhances as more training patterns are added to the neural net.
\end{abstract}

Keywords: Infill, Infill frame, Equivalent Strut, BOPN, Neural Net

\section{INTRODUCTION}

High raised structures are the order of the present day building construction activity. The need for high-raised structures arises due to lack of space, high cost of land and architectural requirements. High raised structures are always vulnerable to loads developed due to natural calamities like earthquakes and cyclones. In addition, there can be calamities due to human induced causes like blasts. The effects described above cause very large amount of lateral forces, due to which the high-raised buildings are subjected to huge over turning moments and shear forces on the foundations. In the past, the buildings were designed only for vertical loads, caused due to gravity loads and imposed loads. The frequencies of occurrence of calamities cause huge loss to both property and life. The governmental bodies are forced to revise the structural design codes frequently to withstand all kinds of disasters.

To counter the effect of lateral forces, the shear walls are provided in building structures. The design methodology of shear walls is included in the design codes. But the large sized shear walls provided in buildings are often considered undesirable from the utility aspect of the buildings. This apart, the other functional utilities of the building are also partly affected due to the presence of shear walls emanating from basement floor to the topmost floor. In this backdrop, the infill contribution to resist lateral loads has come in very handy and research activity is aggressively pursued in this field.
Wall panels are integral part of any beam column framing arrangement. These wall panels though made up of masonry, a relatively weaker material in comparison to concrete, offer substantial lateral resistance to lateral loads by virtue of its larger sectional area. The column members on the other hand are not designed to resist lateral loads. A wall panel bounded by the frame members all around is called infill wall. The reinforced concrete frame inclusive of infill wall is called infill frame. Here, the integral action of the wall and frame is to be considered in evaluating the horizontal load that can be taken up by the infill frame. A general purpose finite element package MSC Nastran is used for the FEM analysis.

As a first step, the flexibility matrix of the frame with infill is evaluated using NASTRAN package. By inverting the flexibility matrix, the stiffness matrix is obtained. The strain energy of the infill frame with a displacement vector of unit displacements corresponding to all degrees of freedom is next evaluated. The strain energy of the frame with infill replaced by two diagonal struts placed in the opposite direction with arbitrary strut width is obtained. The process is repeated by altering the strut widths until such time that the strain energies are equal, which then is termed as an equivalent strut. A large amount of such data is generated by repeating the above process with infill of different aspect ratios of span to height, with and without window/door openings. 
With this large data of information, it is felt appropriate to develop a neural network to evaluate the width of equivalent struts for any arbitrary parameters of infill wall frames. As the input variables and output variables here are of continuous type, the BOPN Neural Net paradigm is found very suitable. The list of input variables include the span, the storey height, the area of the door opening, the area of window opening, the thickness of wall, grade of concrete, the linear/non-linear elasticity of concrete and the single output variable is the width of the equivalent strut. A five layered neural net architecture is selected to simulate the present problem. The $\mathbf{C}^{++}$source code listing for the BOPN neural net is developed to train the data. After successful simulation of training patterns, the results are obtained to satisfaction. As on date, the error in output results that is obtained from the net is a little high, since the numbers of training patterns are too few.

\section{LITERATURE REVIEW}

Smith (1), who had adopted the equivalent diagonal strut concept, had assumed the strut thickness to be the same as that of the infill. He had applied finite difference method to biharmonic equations (expressed in terms of Airy's stress function) to obtain expressions for the Airy's stress function. Using Airy's stress function then, he could determine the stresses in the infill. The subsequent strains in the infill were determined using the stress-strain plots. The diagonal stiffness of the infill was derived from thereon. The finite difference methods adopted by him were considered to be superior numerical techniques during times when finite element concepts were still not clear to many. Sachanski (2) had considered that the action of infill in an infill frame could be affected by transmitting two components of forces, normal and shear, at a finite number of connecting joints, along the frame/infill interface. He had suggested a theoretical solution considering it as a plane stress problem.

Current trends of research on infill frame analysis are mostly finite element oriented. The methods based on finite element approaches are relatively more superior to the other known methods of analysis as they are capable of handling more parameters of unknowns. Mallick and Severn (3) were amongst the first few researches to propose a method based on finite element concept to analyse infill frames. Using this method, the authors were able to find the points of separation between the frame and the infill as well as stress distribution along the contact intervals, as an integral part of the solution. Slip between the frame and the infill was also considered in the study. Saneinejad (6) had proposed a method for the analysis and design of steel frames with concrete or masonry infill walls subjected to in-plane forces. His method was based on both the data generated from previous experiments and results from a series of non-linear finite element (NLFE) analysis. The method accounts for both elastic and plastic behaviour of infill frames considering the limited ductility of infill materials. The method can be used to predict the strength and stiffness of infill frames as well as the diagonal cracking load. He had demonstrated the method by designing the end frames of a four-storey building. $\mathrm{n}$ the absence of rational proposals, totally acceptable to all kinds of situations, methods based on experimental investigations were also proposed by some researchers. Mainstone (4) had explored the influence of various factors like aspect ratio of frames, frame/infill relative strengths etc., likely to have major influence on contribution of infill walls towards resisting lateral loads in multi-bay multistorey framed buildings. Barua and Mallik (5) had proposed an approach summarising the test results of 21 experiments on reinforced concrete frames infill with brick masonry subjected to lateral loads. The tests were performed on prototype structures.

\section{NEURAL COMPUTING}

Neural computing paradigm that is inspired by the functioning of human brain has attracted researchers from almost all disciplines of structural engineering for computerisation of ill conditioned tasks. This computing technology called neural computing, attempts at simulating the functioning of human brain very approximately in a mathematical form. The biochemistry of the neurons is not yet fully understood. Fig.1.1 shows the structure of a biological neuron. The main parts of a biological neuron are the cell body, the axon and the dendrite. The dendrite is responsible for carrying signals from the cell body to the other neurons. The axon on the other hand carries signals from the cell body to other neurons. The dendrite and axon meet at a point called synapses. 


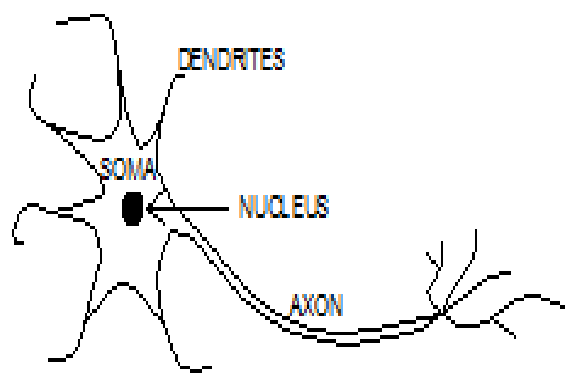

Fig1.1 A BIOLOGIOAL NEURON

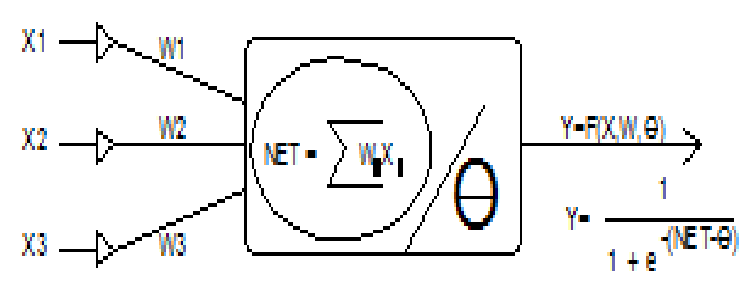

FG.12 ANAFTTACIA. NEURON

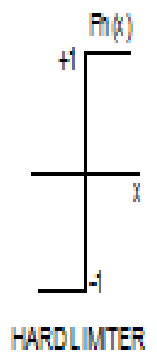

(a)

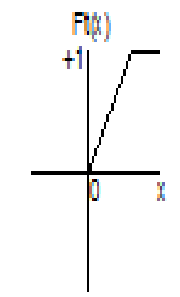

THRESHOLD LOGIC

(D)

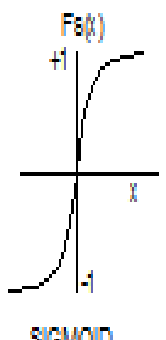

(c)

\section{FIg 13 NODAL FUNCTONS}

Fig 1: Biological and Artificial Neuron

\section{ARTIFICIAL NEURON}

The artificial neuron is an approximately simulated model of the biological neuron. The artificial neuron can carry out only a very simple mathematical function and/or can compare two values. Fig 1.2 shows the essential parts of an artificial neuron. An artificial neuron has a typical function associated to it, which is often called as threshold function or squashing function. A typical artificial neuron gets an input either from other neurons or directly from the environment (i.e. input nodes). The paths connecting the input nodes to the neurons and connections between the various neurons are associated with a certain variable weight, which represents a multiplying factor for the incoming signal representing the synaptic strength of the connections. These weights are initially set to some random values and are later adjusted in the process of training the net. The artificial neuron then sums this input which is actually a weighted sum of all the input signals. The input so obtained is used to calculate a node value according to the squashing function of the neuron. This node value is compared with the threshold value of the neuron and if the node value is higher, then the neuron goes to the "higher state" (excitation state) and a signal is passed on to the next layer of neurons. The three common types of non-linear nodal functions generally used are shown in Fig 1.3.

\section{METHOD OF STUDY}

The infill frame model taken up for study consists of a one bay one storey frame extending to the left and right by one span and extending to the top and bottom by one storey. The frame members are fixed at their farther ends. The infill frame is assumed to be made-up with three different materials. While RCC is used for modelling the beam and column members (two-node 3-D beam elements), brick masonry is used to model the infill wall panel (four-node, plane stress quadrilateral elements). The interface between the frame and infill wall panel is modelled with cement mortar with two-node 3-D beam elements. Whereas, the materials cement mortar and brick masonry are treated linearly elastic, the RCC is considered non-linearly elastic. The infill wall panel is meshed into approximately $200 \mathrm{~mm} \times 200 \mathrm{~mm}$ sized four-node quadrilateral plane stress elements. The bounding frame members all around the infill have been discretised into a number of 1-D elements, so as to facilitate the connectivity with the corresponding nodes of infill panel. The elements connecting the nodes on infill panel boundary with nodes on the bounding frame elements are called link elements. The properties of concrete are obtained from experiments conducted in the laboratory. The properties of mortar and masonry are taken from earlier research papers. A unit force is applied in horizontal direction at the top left hand corner of the infill frame and the elastic static analysis module of MSC Nastran is executed. The displacements corresponding to three degrees of freedom at the top left-hand corner, top right-hand corner, bottom right hand corner and the bottom left-hand corner are recorded in order, which forms the first column of the flexibility matrix. The same process is repeated by applying unit load in turn corresponding to each one degree of freedom and all twelve displacements corresponding to each force application are recorded systematically to form the flexibility matrix of infill frame. Having obtained the flexibility matrix as described above, the matrix is inverted 
to obtain the stiffness matrix (K). A displacement vector (d) is defined with unit displacements corresponding to each one of the twelve degrees of freedom. The strain energy for the infill frame $(\mathbf{U})$ is calculated by the expression: $1 / 2 *$ $\mathbf{d}^{\mathbf{T}} * \mathbf{K} * \mathbf{d}$.
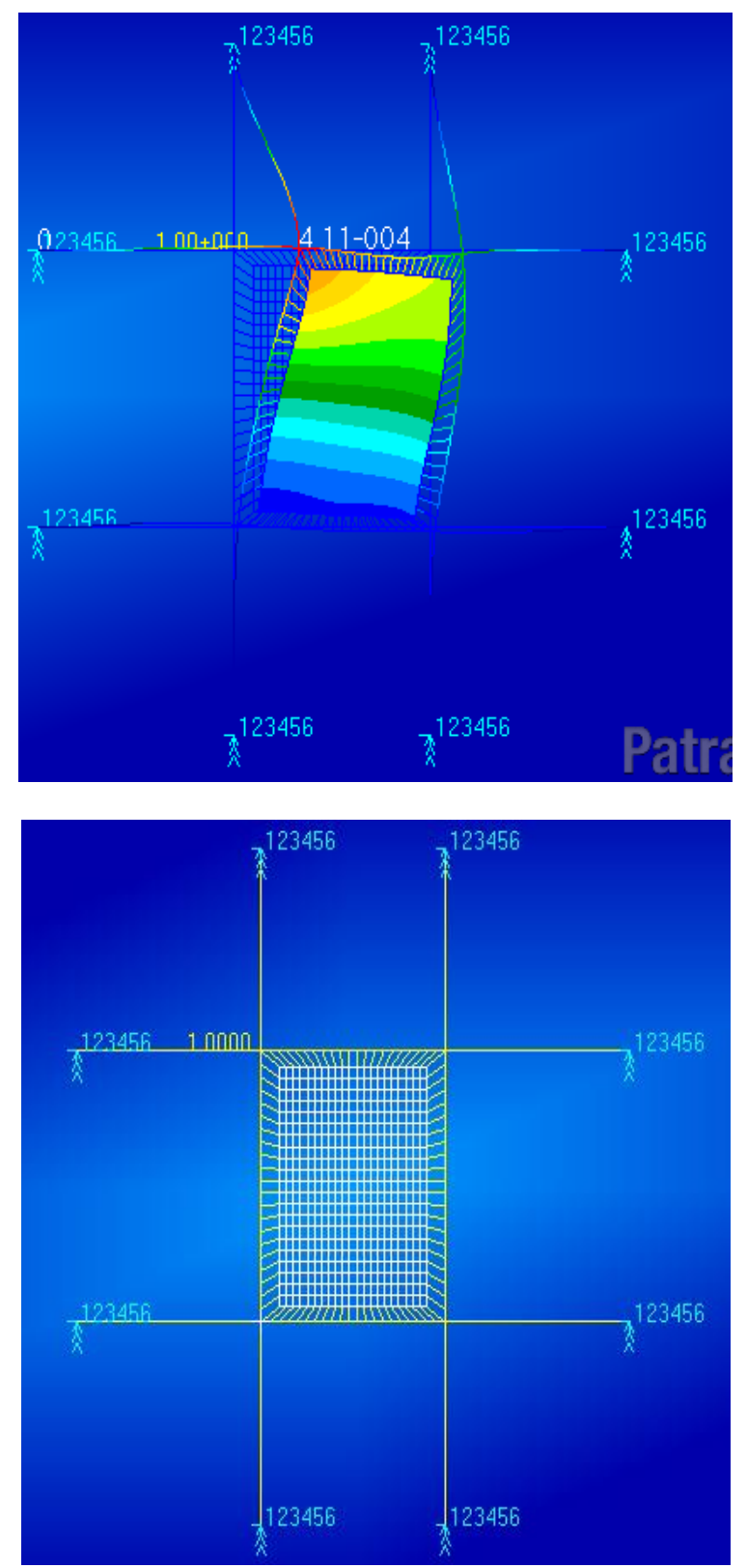

Fig 2: Infill frame with a horizontal force

Grade of Concrete used= M35.

Modulus of Elasticity for RCC is taken from Fig-3, given below:

Modulus of Elasticity of Brick Masonry $=4.217 \mathrm{KN} / \mathrm{mm}^{2}$ Modulus of Elasticity of cement mortar $=2.958 \mathrm{KN} / \mathrm{mm}^{2}$ The stress strain variation of the RC members:

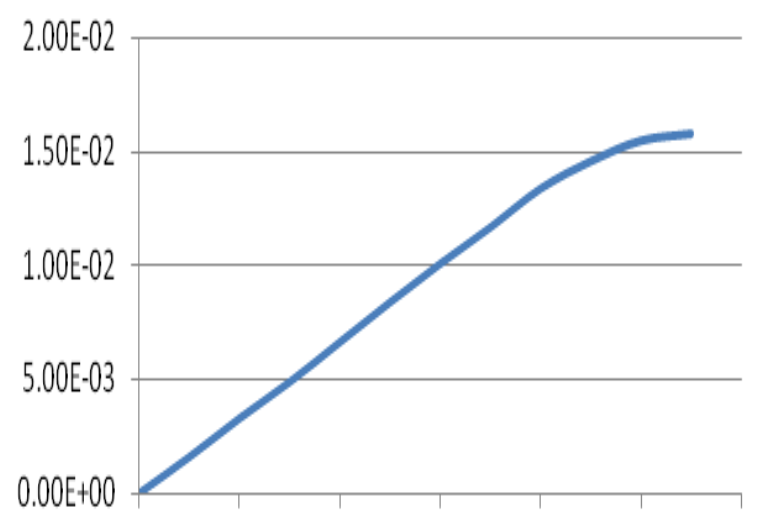

0.00E+001.00E-04 2.00E-04 3.00E-04 4.00E-04 5.00E-04 6.00E-04

Fig 3: Stress vs Strain relation of M35 grade concrete.

The infill wall is next replaced with two diagonal struts connecting the opposite corners of frame made in RCC of arbitrary width. The same process as described above is adopted for obtaining the flexibility matrix, stiffness matrix and the strain energy expression. The value of strain energy obtained is compared with strain energy obtained for the frame with infill. The process is repeated by altering the width of the diagonal struts until such time that the strain energy due to infill is equal to the strain energy due to diagonal struts, which are then referred as equivalent diagonal struts. The aspect ratio of span to storey height is varied and the corresponding equivalent strut widths are determined.

Adopting the same procedure as described above. To make the method more widely applicable, the infill frames with door and window openings have also been analysed and the corresponding strut widths are also evaluated. The data has been tabulated to use it as input training patterns for the BOPN neural net paradigm, generated already.

Since the inputs and outputs for the present problem is continuous type, BOPN Neural Net paradigm is found more appropriate. The set of inputs include the span, the storey height, the area of the door opening(in sq.m), the area of the window opening(in sq.m), the thickness of wall, grade of concrete and modulus of elasticity of concrete and a single output, the strut width. A five layered neural net architecture is selected to handle the present problem. The hidden layer architecture adopted for the present network is 5-3-3. The learning parameter, momentum parameter, noise and error tolerance are varied to minimise the error from the trained neural net. The algorithm is so developed that the weights may either be supplied or can be generated randomly by the software. At present, we have a limited seventy two numbers of training patterns with us. After training the net, the stabilised weight matrices are generated by the software. The error that results from the net is expected to be high since the number of training patterns is not many. With more number of models, a large data of training patterns for strut widths can be generated which would ensure the satisfactory functioning of the neural net paradigm. 
Corresponding to the seventy two training patterns generated as described above, the training is under taken with the neural net simulator to obtain the weight matrices for simulation. To test the validity of the training, one of the training patterns with output is fed as test pattern to the simulator. The output obtained from simulation is compared with the target output. Results corresponding to the test pattern after simulation are available from the list of data files trn.dat, tst.dat, weights.dat, results.dat, res_var.dat some of which are enclosed here.
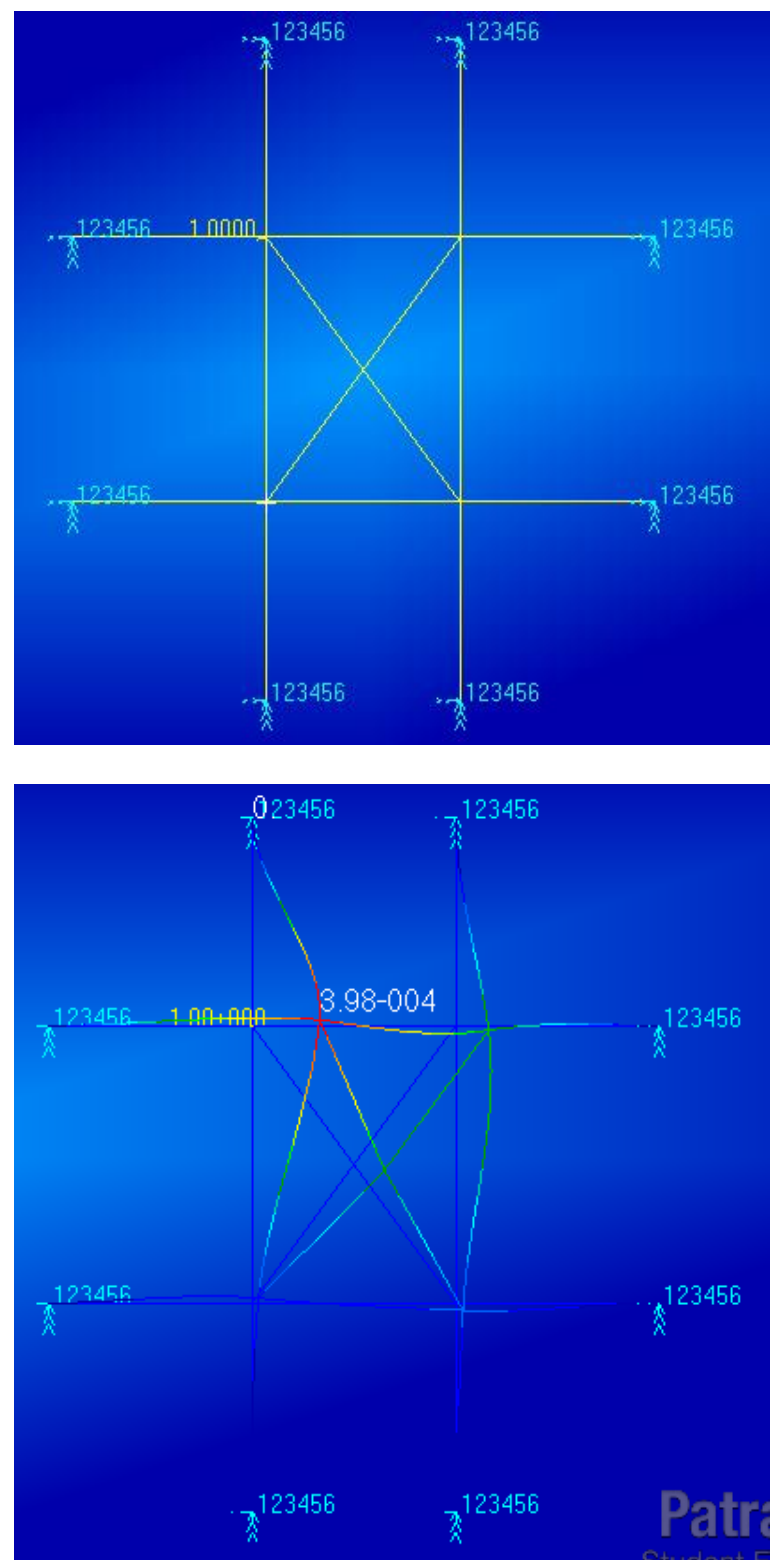

Fig 4: Frame with equivalent diagonal struts

Training data (trn.dat):

$\begin{array}{cccccccc}3 & 4 & 0 & 0 & 230 & 35 & 1 & 500 \\ 3 & 4 & 2 & 0 & 230 & 35 & 1 & 450 \\ 3 & 4 & 0 & 1.2 & 230 & 35 & 1 & 460 \\ 4 & 3 & 0 & 0 & 230 & 35 & 1 & 500 \\ 4 & 3 & 2 & 0 & 230 & 35 & 1 & 450 \\ 4 & 3 & 0 & 1.2 & 230 & 35 & 1 & 470 \\ 3 & 3 & 0 & 0 & 230 & 35 & 1 & 460\end{array}$

$\begin{array}{cccccccc}3 & 3 & 2 & 0 & 230 & 35 & 1 & 350 \\ 3 & 3 & 0 & 1.2 & 230 & 35 & 1 & 400 \\ 3 & 4 & 0 & 0 & 300 & 35 & 0.8 & 450 \\ 3 & 4 & 2 & 0 & 300 & 35 & 0.8 & 400 \\ 3 & 4 & 0 & 1.2 & 300 & 35 & 0.8 & 420 \\ 4 & 3 & 0 & 0 & 300 & 35 & 0.8 & 450 \\ 4 & 3 & 2 & 0 & 300 & 35 & 0.8 & 400 \\ 4 & 3 & 0 & 1.2 & 300 & 35 & 0.8 & 420 \\ 3 & 3 & 0 & 0 & 300 & 35 & 0.8 & 400 \\ 3 & 3 & 2 & 0 & 300 & 35 & 0.8 & 300 \\ 3 & 3 & 0 & 1.2 & 300 & 35 & 0.8 & 350\end{array}$

Test data(tst.dat):
4$$
\begin{array}{ll}
0 & 1.2
\end{array}
$$$$
300 \quad 35
$$$$
350.8
$$

Weights data(weights.dat):

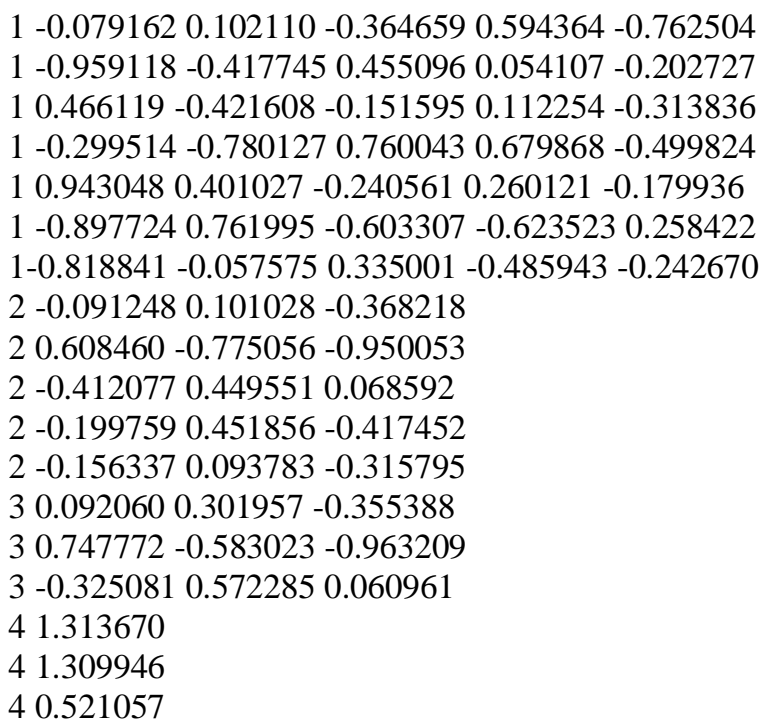

Results file (res_var.dat):

1: First column represents the target outputs for the test patterns.

2: Second Column represents the outputs calculated using the neural net for the test patterns.

3: Third Column represents the length of target output vector.

4: Fourth Column represents the length of error vector.

5: Fifth Column represents the error expressed as a percentage of target output.

$$
420.00416 .21420 .00 \quad 3.79 \quad 0.90
$$

\section{RESULTS AND DISCUSSIONS}

Based on the present study and the results obtained following information are gathered:

1. The lateral stiffness contributed by infill panel is very large even with thin wall panels or wall panels with openings.

2. The position of wall panels with respect to the frame would influence its stiffness contribution.

3. As the aspect ratio increases the stiffness contribution from the panel is increasing. 
4. The grade of concrete of the RC bounding frame has a marginal influence on the infill stiffness contribution.

The equivalent strut dimensions for all the frames with and without door /window openings:

\begin{tabular}{|c|c|c|}
\hline & Linear Analysis & $\begin{array}{ll}\text { Non Linear } \\
\text { Analysis }\end{array}$ \\
\hline \multicolumn{3}{|l|}{$\begin{array}{l}\text { For } 3 \mathrm{~m} * 4 \mathrm{~m} \\
\text { frame: }\end{array}$} \\
\hline $\begin{array}{l}\text { With complete } \\
\text { infill }\end{array}$ & $300 \mathrm{~mm} * 500 \mathrm{~mm}$ & $300 \mathrm{~mm} * 450 \mathrm{~mm}$ \\
\hline $\begin{array}{ll}\text { With } & \text { door } \\
\text { opening } & \end{array}$ & $300 \mathrm{~mm} * 450 \mathrm{~mm}$ & $300 \mathrm{~mm} * 400 \mathrm{~mm}$ \\
\hline $\begin{array}{l}\text { With window } \\
\text { opening }\end{array}$ & $300 \mathrm{~mm} * 460 \mathrm{~mm}$ & $300 \mathrm{~mm} * 420 \mathrm{~mm}$ \\
\hline \multicolumn{3}{|l|}{$\begin{array}{l}\text { For } 4 \mathrm{~m} * 3 \mathrm{~m} \\
\text { frame: }\end{array}$} \\
\hline $\begin{array}{l}\text { With complete } \\
\text { infill }\end{array}$ & $300 \mathrm{~mm} * 500 \mathrm{~mm}$ & $300 \mathrm{~mm} * 450 \mathrm{~mm}$ \\
\hline $\begin{array}{ll}\text { With door } \\
\text { opening }\end{array}$ & $300 \mathrm{~mm} * 450 \mathrm{~mm}$ & $300 \mathrm{~mm} * 400 \mathrm{~mm}$ \\
\hline $\begin{array}{l}\text { With window } \\
\text { opening }\end{array}$ & $300 \mathrm{~mm} * 470 \mathrm{~mm}$ & $300 \mathrm{~mm} * 420 \mathrm{~mm}$ \\
\hline \multicolumn{3}{|l|}{$\begin{array}{l}\text { For } 3 m^{*} 3 \mathrm{~m} \\
\text { frame: }\end{array}$} \\
\hline $\begin{array}{l}\text { With complete } \\
\text { infill }\end{array}$ & $300 \mathrm{~mm} * 460 \mathrm{~mm}$ & $300 \mathrm{~mm} * 400 \mathrm{~mm}$ \\
\hline $\begin{array}{ll}\text { With door } \\
\text { opening }\end{array}$ & $300 \mathrm{~mm} * 350 \mathrm{~mm}$ & $300 \mathrm{~mm} * 300 \mathrm{~mm}$ \\
\hline $\begin{array}{l}\text { With window } \\
\text { opening }\end{array}$ & $300 \mathrm{~mm} * 400 \mathrm{~mm}$ & $300 \mathrm{~mm} * 350 \mathrm{~mm}$ \\
\hline
\end{tabular}

The observations apart, with more sets of training patterns, a better assessment of equivalent strut width can be made. Once the equivalent strut width corresponding to a panel is predicted, as described above, the current structural design software's are good enough to accommodate the lateral strength of infill panels.

\section{LIMITATIONS OF THE STUDY}

1. In the study the properties of masonry and mortar were considered to be linearly elastic, which cannot be true.

2. No penalty factor has been used to take into account the workmanship of brick masonry work.

3. The slip and separation of infill panel along the interface with the bounding frame has not been considered in the study.

\section{REFERENCES}

\subsection{Journal Articles}

[1]. Smith, B.S., (1962). "Lateral Stiffness of Infill Frames" Journal of Structural Division Proc. ASCE, VOL.88, 183199.

[2]. Mallick, D.V., \& Severn, R.T., (1967). "The Behaviour of Infill Frames under Static Loading” Proc. ICE, Vol.38, 639-656.
[3]. Mainstone, R.J., (1971). "On the Stiffness and Strength of Infill Frames" Proc. Inst. of Civil Engineers., London, Supplement IV, 57-90 (Paper 7360S).

[4]. Saneinejad, A., Hobbs, B., (1995). "Inelastic Design of Infill Frames." ASCE Jn. of Struct. Engrs., Vol.121, No.4,634-650.

\subsection{Conference Proceedings}

[1]. Sachanski, S. K., (1960). "Analysis of Earthquake Resistance of Frame Buildings Taking into consideration the Capacity of filling Masonry" Proc. of II World Conf. on Earthquake Engg., III, Japan, 2127-2176.

[2]. Mallick, S. K., \& Barua, H. K., (1977). "Behaviour of One Storey RCC frame Infill with Brickwork under Lateral Loads" Proc. Sixth World Conf. on Earthquake Engg., Vol.3, 3214-3218.

\section{BIOGRAPHIES}

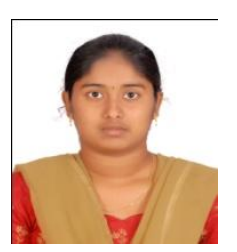

Lavanya Varasala is presently pursuing her M.E(Structural Engineering) in department of Civil Engineering at University college of Engg, Osmania University.

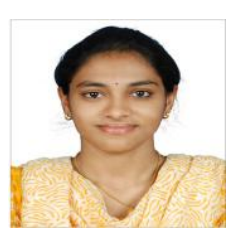

Kandoori Rowena is presently pursuing her B.E(Civil Engineering) in department of Civil Engineering at University college of Engg, Osmania University.

P.Anuradha is presently working as assistant professor of Civil Engineering at University college of Engg, Osmania University.

Murali Krishna . N. is presently working as professor in the department of Civil Engineering at University college of Engg, Osmania University. 